\title{
Stasis and change: social psychological insights into social-ecological resilience
}

\author{
Elizabeth V. Hobman ${ }^{1}$ and Iain Walker ${ }^{2}$
}

\begin{abstract}
Ecologists have used the concept of resilience since the 1970s. Resilience also features in many of the social and economic sciences, though in a less central role and with a variety of interpretations. Developing a fuller understanding of the concept of socialecological resilience promises advances in how science can contribute to achieving better environmental outcomes, locally and globally. Such a development requires articulation of different perspectives on resilience and critical engagement across those perspectives. We present, in some detail, a particular perspective on resilience developed by the pioneering social psychologist Kurt Lewin. We suggest that Lewin's explicit use of social-ecological systems in his framework presaged much of the current social-ecological understanding of resilience. We set out some key details of his framework, notably the characteristics of his field theory, his use of group dynamics as a vehicle for social change, his introduction and development of the principles of action research, and his three-step change model. We conclude by mentioning some areas of the framework that are under-theorized or not theorized at all.
\end{abstract}

Key Words: action research; Kurt Lewin; resilience; social ecology

\section{INTRODUCTION}

Resilience refers to the capacity of an individual, group, or system to respond and adapt to some type of stress or disturbance in such a way that functionality is maintained. It is used, albeit with varied definitions, across a range of disciplines, such as engineering, economics, environmental science, psychology, and sociology (Bahadur et al. 2013). In the environmental and social science domains, it is increasingly recognized that a blend of resilience thinking is required because social and ecological systems, or more simply, people and nature, are fundamentally interconnected in what is known as overarching coupled socialecological systems (SESs; Folke 2006, Bahadur et al. 2013). Thus, the resilience of SESs, known as social-ecological resilience, has emerged over the last decade as a rapidly growing research field in its own right (Brown 2014). Its transdisciplinary breadth has provided opportunity for researchers across the sciences to collaborate on a range of critical issues, predominantly in the areas of disasters, climate change adaptation, and natural resource management, in which the capacity to cope with change, to learn, and to adapt is requisite for the longevity of SESs (Adger et al. 2005, Gunderson 2006, Walker et al. 2006, Marshall and Marshall 2007, Cutter et al. 2008, Bohensky et al. 2010, Zhou et al. 2010, Biggs et al. 2012).

Revealing its roots in ecological rather than social science, socialecological resilience has been defined as "the capacity of the system to absorb disturbance and reorganise while undergoing change so as to still retain essentially the same function, structure, identity and feedbacks" (Walker et al. 2004). Thus, it essentially comprises two distinct yet overlapping properties: the persistence or maintenance of SES structure when facing immediate disturbances and the adaptive capacity or transformability needed to sustain function under long-term pressures (Walker et al. 2006). Much research on SES resilience has focused on the first property of maintenance, i.e., the capacity of the system to withstand disturbance and simply bounce back to its original state. However, understanding that there is more to resilience then simply being capable of absorbing disturbance, researchers have recently started to emphasize the additional forward-looking components of adaptive capacity and transformability; properties that both speak to adapting to and/or preparing for uncertainty and surprise (Walker et al. 2004, Folke 2006, Folke et al. 2010, Brown 2014).

Adaptive capacity is about the degree to which the system is socially, i.e., by human action, capable of self-organization and can build and increase the capacity for learning, change, and adaptation in response to changing external drivers and internal processes (Carpenter et al. 2001, Klein et al. 2003, Walker et al. 2004). Transformability, on the other hand, concerns the capacity of a system to "cross thresholds into new development trajectories," creating "a fundamentally new system when ecological, economic or social structures make the existing system untenable" (Walker et al. 2004:5). From a whole-of-system viewpoint, it is considered that such deliberate and profound transformational change of SESs is needed to ensure that the entire Earth's system persists in the Holocene stability domain (Folke et al. 2010). This renewed perspective on adaptive resilience emphasizes the importance of social change in establishing resilient SESs. Importantly, these change efforts need not be instituted at a large scale. Indeed, it has been suggested that transformational change at smaller scales and in a gradual way, which is more manageable and usually less costly, can enable resilience at larger scales because of the interlinked and crossscale nature of SESs (Folke et al. 2010). And fortuitously, such small-scale efforts also mean that various experiments can be conducted, either in controlled laboratory settings or in the field, to identify the most impactful and cost-effective change initiatives.

Although deliberate transformation is certainly being advocated as a way to break down old, untenable systems to create new, resilient systems, current efforts to understand and practice social change in the realm of social-ecological resilience are still exploratory. We seek to advance this endeavour by returning to the classic literature of Kurt Lewin (1890-1947), a man who

${ }^{1}$ Commonwealth Scientific and Industrial Research Organisation, University of Queensland, ${ }^{2}$ Commonwealth Scientific and Industrial Research Organisation, University of Western Australia 
Fig. 1. A Lewinian field theoretical approach to understanding social-ecological systems (SESs).

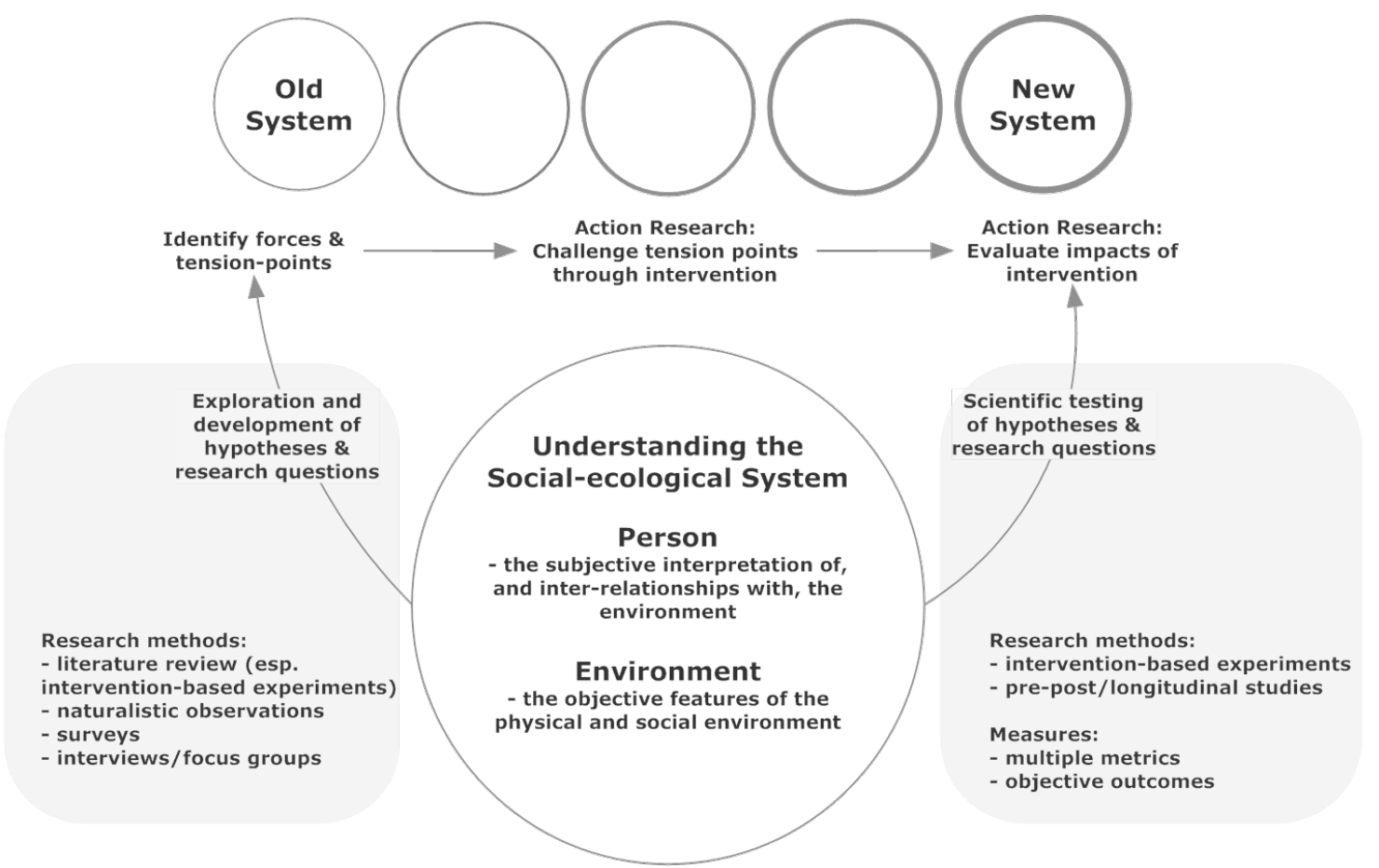

pioneered work on social change, especially the resolution of social conflict, and who explicitly brought ecology into psychological theorizing some 70-odd years ago. Despite his efforts, as well as the work of later psychologists (Gibson 1966, Barker 1968, Bronfenbrenner 1979), ecological ideas have not fully or firmly established themselves in mainstream psychological thinking (Oishi and Graham 2010, Heft 2013, Oishi 2014). However, with increasing recognition that many of the earth's SESs are in a state of crisis, it would appear that we are now on the precipice of a renaissance in social-ecological psychological research and practice. By revisiting Lewin's theoretical frameworks for understanding and effecting social change, and embellishing his approach with that of later advances in ecological psychology, cognitive psychology, social psychology, and sustainability science, our aim is to advance our thinking about social-ecological resilience from a social change perspective and to help stimulate and shape dialogue between scholars in social-ecological resilience and in psychology.

\section{LEWIN'S FIELD THEORY APPROACH TO SYSTEM STASIS AND CHANGE}

Motivated to solve a range of pressing societal issues, Lewin developed four mutually reinforcing and supporting elements of a broader approach to understanding behavior and achieving social change: field theory, group dynamics, action research, and the 3-step change model (Burnes 2004). The hallmark of Lewin's approach was the conceptualization of problems and the determination of change from a whole-of-systems or Gestalt perspective. And the cornerstone to this endeavour was field theory, which Lewin defined as "a method of analysing causal relations and of building scientific constructs" (Lewin 1951, c1943a:45), or more specifically, the determination of the total field, in terms of external drivers and internal forces, which ultimately characterize a situation or system. Figure 1 provides a graphical summary of this approach to understanding system stasis and change.

Lewin recommended that field theory should proceed by first characterizing the field at a whole-of-system level and then isolating and analyzing various smaller parts in a more detailed fashion (Lewin 1951, c1942:62). Additionally, two facets of the field should be assessed: the objective features of the environment, i.e., nonpsychological factors, which serve as boundary conditions on how humans act in the field; and the subjective interpretation of the environment, i.e., psychological factors, which reflects how actors in the system perceive and interact with the immediate objective environment. But importantly, only those factors, which have demonstrable effects on the individual, group, or other entity under study, no matter how distal or unconscious, are considered to be part of the field (Cartwright 1951). Lewin even used the term life space synonymously with the field to represent the psychological field of constantly changing, interdependent, and interacting forces, which ultimately influences the life of an individual within a system. This is also more simply expressed in the well-known formula: behavior $=f$ (person, environment) $=f$ (life space; Lewin 1951, c1946). Although Lewin tended to focus on understanding and changing the field or life space of individuals and groups, it is important to note that life space can refer to any system that comprises humans, e.g., community, organization, society (Cartwright 1951).

In social-ecological terms, the field or life space may be taken as the social-ecological system that surrounds a human entity, i.e., 
an individual, group, community, institution, or society. From a comparative point of view, it also appears that field theory itself is commensurate with many of the core principles of socialecological research. For example, in social ecology, environment settings can be defined in terms of the objective and subjective qualities, as well as in their immediacy, i.e., proximal versus distal, to human entities who may be the subject of study at multiple levels, i.e., individuals, groups, communities, and societies (Stokols et al. 2013). And of particular reference to building resilient SESs, social ecologists underscore the importance of interdependencies among local and distal environments, and the complex interactions between humans and their environment as critical determinants of the resilience of the overall SES (Stokols et al. 2013), principles that resonate with Lewin's field theoretical approach.

\section{Analysis of the objective environment, i.e., psychological ecology} To define the field or life space, Lewin first examined the objective, nonpsychological environment, a process he called psychological ecology, which is positioned at the boundary zone of the life space; this is the point at which psychological, i.e., subjective, and nonpsychological, i.e., objective, factors intersect (Lewin 1951, c1943b). This involves identifying objective, contextual, or environmental factors, which serve to constrain, limit, or put a boundary upon what can actually happen within the system, or, more simply, any objective factor that affects the human entity under question. These factors might be so diverse to be classified and studied in separate spheres, e.g., physical, economic, political, and legal processes, yet, in field theory, they are supposed to be examined together as a "single coherent system of constructs" (Cartwright 1951:xii). Importantly, the characterization of these nonpsychological variables helps isolate significant factors, i.e., those that conceivably have an impact on the stability of the system, which should receive more in-depth psychological analysis at a later stage (Lewin 1951, c1943b).

Unfortunately, Lewin did not extrapolate a great deal on how to analyze the broader objective environment; his primary focus was on how individuals perceive their immediate environment because it is the interaction between the person and environment that governs behavior. He did, however, develop channel theory, a method that explores the social and economic structure through which events flow, enabling the identification of critical regions in the life space in which strong forces are present, i.e., gates, and often marshalled by decision makers who can open or close paths, i.e., gatekeepers (Lewin 1947a, b, 1951, c1943b). This social channel analysis can be considered a descriptive or diagnostic study into the objective environmental field surrounding the behavior/issue, with the aim of identifying gatekeepers and critical pathways.

As an example of channel analysis, and as part of the U.S. war effort to encourage households to consume nontraditional forms of meat, Lewin studied why people eat what they eat (Lewin 1951, c1943b). To address this question, he sought to understand how food comes to the table and why, which necessarily involved examining the various channels, e.g., gardening and buying, through which food reaches the table, and who controls these channels, i.e., the gatekeepers. After performing such an analysis, he then probed the psychology of the gatekeepers to understand the factors that determined their decisions and how the gatekeepers might be influenced. Channel analysis is a technique that could be applied to any system in which there are channels or pathways involving decision makers at critical junctures. Indeed, channel analysis may bear some resemblance to contemporary supply-chain, value-chain, and life-cycle analyses, a suite of system-based approaches commonly used in business to examine various aspects, e.g., the allocation of resources, information dynamics, resource utilization, and/or environmental impacts, associated with the flow of products, services, finances, and information from the initial producer/supplier to the ultimate customer (Fearne et al. 2012, Soosay et al. 2012). Importantly, recent research is starting to conceptualize and explore resilience within supply chains, in an effort to better understand and manage external risks to supply chains (Ponomarov and Holcomb 2009).

Lewin's student, Roger Barker, and his students in turn, also went on to develop more systematic, descriptive methods and approaches for assessing the objective, natural environment or ecology in which behavior occurs, which they termed the behavior setting (Barker 1968, Schoggen 1989). Barker viewed behavior settings as self-regulated systems that serve to regulate the expression of behavior and tend to be associated with somewhat predictable behavioral patterns, known as collective patterns of action (Deutsch 1968, Heft 2003, Jenkins 2008). Thus, each behavior setting comprised both the physical setting itself, i.e., the milieu, and the corresponding behavior, i.e., the collective pattern of action, (Barker 1968, Schoggen 1989). This analysis was consistent with Lewin's discussion of psychological ecology, as the determination of physical or social environmental conditions that place a boundary on behavior, i.e., enable or constrain what people can actually do in the setting. His analysis focused on the unitization and classification of behavior settings with the aim of identifying regular behavioral patterns expressed at a single, more macro- or molar- level of analysis, i.e., community-level. In comparison, Lewin's channel theory sought to diagnose the flow of events and processes across levels within the entire ecosystem, and his analysis of behavior tended to focus on patterns at the microlevel, within and across individuals and small groups.

Although both approaches are useful in understanding resilient SESs from the perspective of identifying ecosystem strengths and weaknesses, Barker's behavior setting analysis appears to hold special worth as a strategy to help build resilience in communities, particularly those at risk of experiencing or recovering from disasters and/or other major disturbances such as hurricanes, floods, war-torn conflict, poverty, and disease epidemics. A thorough behavior setting analysis can reveal critical insights into the types of ecosystem services and policies that might build, versus threaten or reduce, social-ecological resilience in the community, as well as the alternative forms of community capital that might be cultivated by different categories of services. For example, research has suggested that the presence of green space in the built environment, and in particular, those green spaces that are developed and managed by the community itself, provides multiple services to the ecosystem, and thereby fosters the development and maintenance of different forms of community capital reflective of resilience, e.g., social and human capital in terms of more cohesive and positive social interactions; improved psychological and physical health and improved memory, learning, and self-regulation; environmental capital in terms of climate-proofing cities and reducing energy consumption (Tidball 
and Krasny 2007, James et al. 2009, Kaplan and Berman 2010). By conducting an ecosystem services analysis of different classes of behavior settings, e.g., physical infrastructure and social services, such as public transportation, health, education and welfare services, recreation areas, green spaces, and community social events, in and across communities, as well as across countries and cultures, it may be possible to identify the appropriate mix of services and policies, which is required to build and maintain a range of community capital reflective of a resilient SES.

To be clear, this ecosystem services analysis should also include an assessment of how individuals collectively act in response to these services, because a behavior setting analysis is not purely about the objective environment, but also about the collective patterns of action that correspond to it. The importance of doing so is underscored when we consider that behavior settings naturally set the scene for the development and continuation of socially normative practices (Heft 2001, 2003, 2013), which are basically patterns or behavior considered normal within one's social milieu and which exert a strong influence over individuals to conform. Inevitably, it is through collective patterns of action that many of the human capital dimensions, e.g., psychological and physical health, positive social relations, to community resilience might accrue.

Finally, it is worth noting that although behavior settings analysis was originally conceived in public social life, the same likely occurs in the private sphere, i.e., within a person's home. As discussed in the sociological literature, there is an inextricable link between the objective environment, in terms of technologies, appliances, infrastructure, such as advances to plumbing enabling private bathrooms to be constructed within a house, and the development of household air-conditioning, and the emergence of socially normative practices in and around the home, e.g., resourceconsuming social practices of daily cleaning and laundering, and reliance on space heating and cooling (Shove 2003a,b). Although many of these collective practices have emerged across a long time frame, i.e., across generations, and are culturally imbued, it is worth reflecting on how the objective environment, in terms of the services it provides to people, has ultimately shaped what socially normal practice means within a given society, and whether the same process might also be able to refashion the mix of ecosystem services to promote conservation rather than consumption in households, communities, and societies.

\section{Analysis of the subjective environment, i.e., life space}

Although we present psychological ecology as separate to life space analysis, both analyses are entwined and interdependent. Indeed, the assessment of the objective environment is an integral step in understanding the boundary conditions of the life space of the human entities embedded or nested within that environment. This is because certain physical and social structures, services, events, and processes, and the collective patterns of action, at higher levels serve to control or define the behavior exhibited by individuals and groups at lower levels: in Lewin's terms, the psychological ecology, i.e., assessment of nonpsychological data, "determines the boundary conditions of the life of the individual or group" (Lewin 1951, c1943b:170). Thus, much of Lewin's work focused on understanding the field or life space at an individual or small group level, although the concept can just as well be applied to larger groups and institutions, so long as a human entity is part of the collective (Cartwright 1951).

The fundamental proposition of life space is that behavior can be understood and thereby changed, by considering the psychological relationship between a person and his/her environment. Lewin understood that a person responds to a situation based on their direct perceptions and mental construal of the situation, i.e., how they perceive, interpret, and understand stimuli in the world around them, and not necessarily to the objective features of the situation. Because he was most interested in motivational problems, he explored the perceived environment as it exists for the person (Lewin 1951, c1943b, Deutsch 1968). Using the same example of why people eat what they eat, in addition to diagnosing the channels, Lewin interviewed gatekeepers who controlled the channels, i.e., housewives who were largely responsible for food purchasing and preparation. $\mathrm{He}$ assessed the usual foods consumed by different types of household members and at different times of the day, group differences in the value attached to certain foods, the symbolic role of food in family life, and cultural differences in eating practices. He elicited information on cognitive structure, i.e., the terms in which people think and speak about food, and motivation, i.e., the system of values behind their choice of food, their food needs, and obstacles, to understand their decisionmaking processes and how they might be influenced to modify their choices to make better use of rationed food choices (Lewin 1951, c1943b).

Although verbal report was Lewin's usual method for identifying the properties of life space (Deutsch 1968), by Lewin's own commentary, he also cautioned against treating verbal reports as an expression of fact and recommended treating them as though they were, instead, a projective technique, because they are also, always, a reaction to the situation itself, e.g., how the question was framed, how the individual was feeling on the day (Lewin 1951, c1943-44). He even stressed the need to "most urgently" develop "a real theory of questionnairing and interviewing which offers more than a few technical rules" (Lewin 1951, c1943-44:163). We suggest that additional techniques, e.g., naturalistic observations of a representative sample, longitudinal assessment, using data from multiple sources, archival data, and physical traces (Webb et al. 1966), ought also to be used to triangulate data to yield a better approximation of how reality exists for the person.

Moreover, later work in ecological psychology has helped elucidate life space from a perceptual as well as a motivational perspective, thereby suggesting additional and possibly better ways of evaluating the properties of life space beyond that of verbal self-report. A social-ecological framework of attitude and behavior changes outlines three key principles of how individuals perceive and interact with their environment: affordances, attunements, and effectivities (Baron and Misovich 1993, Kurz 2002, Kurz et al. 2005). The overarching principle of affordances, developed by Gibson (1979) in relation to visual perception, represents the idea that objects and/or features in the environment are perceived by a person in terms of the object's functional significance or utility, e.g., a hot shower affords warmth, cleanliness, and comfort. Ultimately, "the affordances of the 
environment are what it offers the animal, what it provides or furnishes for good or ill" (Gibson 1979:127), and they therefore guide action. Rather than involving higher-order cognitive processing, the perception of affordances is considered to occur simply through direct experience with an object in situ (Heft 2003, 2013). Affordances are analogous to Lewin's concept of valence (McArthur and Baron 1983), the 'pull' of a collection of psychological forces in the life space, expressed dimensionally as negative/unfavorable, i.e., movement away from the object, versus positive/favorable valence, i.e., movement toward the object (Lewin 1951, c1946), but Gibson's articulation more fully describes the nature of affordances, characterizing the worth of the object to the person in a contextually rich and action-centred way.

Although affordances are directly perceived, they are constrained or shaped by the nature of the perceiver through individual differences and state-based differences. In Lewinian terms, the presence and strength of valence depends on the individual's state of needs because "the valence of an activity is related to its consummatory value for satisfying the need" (Lewin 1951, c1946:274), e.g., the need for relaxation raises the valence of reading. This gives rise to the second principle of attunements, which represents the fact that individuals can be attuned to different affordances, with those affordances that are more meaningful to the moment potentially being more salient than less meaningful ones. For example, when perceiving and interacting with objects that are environmentally relevant, it has been said that the primary, instrumental affordances, e.g., cleanliness, or transportation, are usually the most salient, whereas environmental-impact affordances are typically not perceived (Hormuth 1999, Kurz et al. 2005). This idea resonates with sociological research on the social and cultural conventions for comfort, cleanliness, and convenience associated with everyday energy-consuming, social practices (Shove 2003a). The final principle of effectivities refers to the knowledge and skills, i.e., competencies, required to use the object to yield its affordance. This principle is similar to Lewin's discussion about learning as a change in knowledge about how to perform certain behavior (Lewin 1951, c1942).

Despite the importance of affordances in understanding how humans interact with their environment, mainstream psychology has given them little attention. Heft (2003) explained that this marginalization is partly because of "the fact that psychologists have usually considered the character of perceiving from a detached stance, and then reified the results of this analysis... rather than attending to the immediate flow of perception-action" (Heft 2003:149). Because affordances are perceived in an experiential way in which "awareness sinks...to such an extent that encounters with the world seem nearly automatic and habitual" (Heft 2003:151), they are not something that can be easily observed from a detached point of view. This process resembles the well-known phenomenon in social cognition that people often lack direct introspective access to their own attitudes and perceptions (Nisbett and Wilson 1977, Greenwald and Banaji 1995). Rather, social behavior often operates implicitly, only accessible via indirect means. Thus, it is possible that affordances can be studied more validly in controlled experiments in which the environment is systematically changed to prime or cue the affordance, e.g., by way of labels that attune people to alternative affordances, and subsequent action is objectively measured, as has been shown in the area of household energy and water conservation (Kurz et al. 2005).

Another important consideration when analyzing life space is that humans are susceptible to biases when processing information, making decisions, and making behavioral choices in and about their environment. Particularly in contexts of complexity, uncertainty, and risk, i.e., features that are common to all sustainability issues, individuals tend to adopt decision-making shortcuts, e.g., discounting outcomes that occur further into the future as opposed to those that happen more immediately, basing decisions on feelings rather than on objective assessment of risk, believing information that more readily comes to mind, rather than resource-intensive, in-depth reasoning to make a judgement or choice (Kahneman 2003, 2011, Thaler and Sunstein 2008, Dellavigna 2009). Although these heuristics help conserve scarce and valuable cognitive resources, they also tend to be associated with faulty decision-making processes, and therefore often result in errors in judgement and suboptimal outcomes for the person and the environment. In analyzing life space, then, it is important to keep in mind that many, if not all, of the actors in a SES, including experts, are likely to use such cognitive heuristics. If such actors are critical gatekeepers, their biased decision-making and behavioral choices could contribute to suboptimal and hence, less resilient, SESs.

A final but important issue of relevance to the subjective environment, and one repeatedly raised by Lewin, is the principle of contemporaneity, the idea that any behavior or change in the field can only be explained by what is occurring in the life space at that time (Lewin 1951, c1943a). Both the past and the future can only influence behavior through being represented in the contemporaneous life space of an individual. Indeed, this principle is in "contrast both to the belief of teleology that the future is the cause of behaviour and that of associationism that the past is the cause of behaviour" (Lewin 1951, c1940:27). In establishing the principle of contemporaneity, Lewin did not intend to mean that neither the past nor the future has an impact on the current situation, to the contrary, he explained that the psychological past, present, and future are all represented in life space at any given time, which he termed time perspective. This representation is possible via understanding an individual's subjective view of their objective environment in reference to all time periods (Lewin 1951, c1946). In this way, past influences, as well as aspirations, expectations, hopes, plans, and goals for the future, all together, feature in the current situation (Lewin 1951, c1942).

In sum, life space analysis comprises a descriptive assessment of both the objective and the perceived environments. In combination, this assessment can describe the total system in terms of forces that maintain the system's quasi-stationary equilibrium or its steady state during a period of stability. By using the term quasi to describe the system's stable state, Lewin was highlighting the simple fact that the strength of forces within a system are always continuously changing despite the outward expression of no change in the total system. That is, even during periods of system stability, change within the system still occurs; and so long as the forces sum to zero, termed a positive central force field, the system will continue to gravitationally fluctuate 
around an average level (Lewin 1947c). Because system change and stability are relative concepts, it naturally follows that the level of quasi-stationary equilibrium can be changed, if so desired, by modifying the forces within the system. With this in mind, life space analysis can therefore be viewed as a system change management tool. It not only can describe the features of a quasi-stationary, steady-state system, but it also can provide testable hypotheses on where, when, for whom, and upon what to focus subsequent change efforts, if indeed the intention is to modify the system to achieve a more desirable state. Importantly, these efforts to effect system change should be conducted using experimental approaches, with the outcomes unequivocally demonstrating the strength of the targeted forces within the system (Lewin 1951, c1943b). Through what is now known as the research areas of group dynamics and action research, Lewin used field theory to create social change and in so doing, demonstrated the practical utility of understanding the dynamism of the forces in life space.

System change, group dynamics, and the three-step change model Within any system, various forces on behavior differ in intensity and direction. Once we have identified these forces through life space analysis, we can intervene in some way to counter-lever forces in such a way that only a little pressure is required to change the entire system, moving it toward a new quasi-stationary equilibrium. This is labeled a low-pressure change method and contrasts with high-pressure change, which is the leveraging of forces in a single direction only, something to be avoided, if possible, because it creates an unfavorable, high-tension system (Lewin 1947b, c). Lewin undertook much experimental work, designing and testing interventions targeting such forces to achieve social change. Even though his efforts primarily centred on individual- and group-level change, he did argue that the same approach could be applied to problems at broader levels in a system. Indeed, because it is the essential structure and forces within a system that matter, not the size or scale, Lewin even suggested that some higher level problems could usefully and more practically be examined at a smaller scale (Lewin 1951, c1943-44). The key to success for this approach is creatively simulating the same pattern of forces that occur at the macrolevel and transposing them onto a smaller scale model (Lewin 1951, c1943-44).

Lewin's planned approach to change viewed social change as an explicit, conscious, democratic process best undertaken within the individual's social milieu. All of his remaining approaches, i.e., the 3-step change model, group dynamics, and action research, proclaim the essential component of active involvement on the part of participants. Lewin believed that to overcome the major force of individual resistance to behavior change, it was essential to first increase individual awareness of current behavior and build intrinsic motivation or felt need to learn and change. This process is articulated as the first stage of change, i.e., unfreezing, whereby the quasi-stationary equilibrium of human behavior is destabilized, leaving itself malleable to change. It should be noted though, that most of Lewin's change efforts concerned behavior that expressed stickiness in terms of social habit or custom, which he regarded as group standards that have social value, and therefore demonstrate strong resistance to change (Lewin 1947a). Thus, his social change efforts tended to occur at the group level. He developed deliberative or participatory approaches, whereby individuals met as a group to freely discuss and make decisions regarding a specific issue. These group processes therefore not only served to unfreeze individuals from past habits, but also moved them toward developing and practising new behaviors consistent with the group standard, i.e., the second stage of moving. Once new group standards for behavior are established, such behaviors are then supported and maintained as per the final stage of system refreezing. Group-based interventions based on Lewin's approach have been applied in the field of sustainable consumption in households, although questions remain about the cost-effectiveness of rolling out such interventions to the broader population, i.e., beyond those who are proenvironmentally disposed (Hobson 2003, Staats et al. 2004, Hargreaves et al. 2008).

Lewin explained that one of the reasons why the group situation is influential is because individuals are generally unwilling to deviate too far from group standards for fear of being outcast from the group (Lewin 1947b). As a result, most individuals conform to the standard of the group to which they belong. There is now ample evidence of the power of social conformity and influence (Cialdini et al. 1990, 1991, Cialdini and Trost 1998). Interestingly, this work has even demonstrated that normative social influence does not require direct observation of, or interaction with others, because social conformity can occur simply by knowing the social standards or norms, which may be conveyed via nonpersonal and more cost-effective means, such as written messages, information, or signs (Goldstein et al. 2008). That is, the effects occur implicitly, without the individual being consciously aware that they are indeed following the behavior of others (Nolan et al. 2008).

\section{Other channel factors}

Although much of Lewin's social change efforts focused on group influence, his exposition of field theory and channel theory also recognized additional possibilities for modifying other aspects in the life space, particularly at crucial gates, in which powerful forces and gatekeepers may significantly constrain or facilitate change (Lewin 1951, c1943b). In channel theory, he referred to small, often seemingly inconsequential, yet critical forces, processes, or features in the channels/life space, which could be leveraged to dramatically change the entire system. Similarly, Barker's (Barker 1968, Schoggen 1989) critical observation that behavior varied less between children in the same setting, than it did across settings, suggested that the environment has a large influence on behavior. Thus, the manipulation of some small aspect in the life space or channel was the fundamental change key that Lewin advocated, and it is this idea that is present in much of the contemporary literature in social psychology and the decisionmaking sciences. This research demonstrates how small contextual or environmental changes, which accord with how humans process information and make decisions, can efficiently and economically influence people's and groups' behavior (Thaler and Sunstein 2008, Dolan et al. 2010, 2012, Metcalfe and Dolan 2012). Consistent with field theory, critical modifications to the objective environment invariably influence the individual's subjective environment, leading to a change in the overall functioning of the system. These types of interventions can be implemented at various levels in society, e.g., city planning to provide efficient transportation systems, the provision of public bicycles to foster human-powered transportation, manufacturers 
setting the cold-wash cycle on washing machines as factory default, and establishing participation in new programs as optout rather than opt-in, with the choice of intervention depending on such things as implementation costs and expected benefits, including likely return-on-investment. Collectively, these strategies are known as upstream interventions to represent the fact that they support the development and maintenance of new SESs (Verplanken and Wood 2006).

There is also merit in considering downstream-plus-contextchange strategies, i.e., the delivery of information/education to target an individual's psychology, i.e., attitudes, beliefs, values, knowledge, and goals, at critical moments in a person's life, e.g., when moving house, purchasing an appliance, or having a baby. At these moments, many proximal environmental constraints are loosened, and hence individuals may be more open to learn and change (Verplanken and Wood 2006). This situation can be likened to Lewin's notion of felt need, in which change is an explicit conscious process driven by an individual's own motivation to change.

\section{Interventions: interdependencies and action research}

Given a distinction between the objective and subjective environments, interventions might reasonably be contextually based or psychologically focused. But the initial distinction is subtle and perhaps moot. Because field theory posits that the perceived environment represents an individual's psychological view of the objective environment, any changes in the objective environment, e.g., providing information and education, or some form of physical infrastructure/service such as public bicycles, naturally exert a corresponding change in the perceived environment. Thus, more important than deciding whether to focus an intervention on the objective or the subjective environment are the tasks of developing and coordinating any such intervention and designing studies in such a way that the intervention's impact, and cost-effectiveness, can be measured on important dimensions across multiple levels of analysis.

There are various capitals or resources available in society for social actors to achieve goals. Identifying and understanding how these capitals interact is critical when seeking to effect SES change. Because capitals are interdependent upon and interact with each other, sometimes negative, perverse, or unintended outcomes can result from intervention efforts (Stokols et al. 2013). For example, an improvement in one community capital, e.g., economic prosperity through employment at a landfill plant, may lead to a decline in another capital, e.g., natural capital in terms of reduced air quality, creating a temporarily untenable social-ecological system, which could then mobilize another type of capital, e.g., social capital in terms of organized protests and petitions, in an effort to reach a new state of system stasis (Stokols et al. 2013). Another example is the introduction of chlorofluorocarbons, i.e., Freon, as a refrigerant, which improved one capital immediately, i.e., human capital in terms of greater safety, because previously used sulphur-dioxide refrigerant causes corrosive injury, but also resulted in the decline of another capital, i.e., environmental capital in terms of ozone depletion, and would have eventually adversely affected the full gamut of capitals had corrective action, i.e., the Montreal Protocol, not been undertaken to eliminate the production of chlorofluorocarbons.
Thus, when determining where, when, and how to invest with the aim of improving SES resilience, it is important to consider the entire system, i.e., generalized resilience, over time and space, rather than specific parts of the system at one time only, i.e., specified resilience (Folke et al. 2010). This echoes Lewin's recommendation to first characterize the entire field from a whole-of-system point of view before focusing on smaller subparts. The dictum becomes relevant again when it comes to systematically evaluating interventions to ensure that no immediate or longer-term negative consequences result across a range of capitals. This need for systematic evaluation introduces Lewin's notion of action research, a research paradigm or practice, which serves to connect the theorist and applied psychologist via the realization that "there is nothing so practical as a good theory" (Lewin 1951, c1943-44:169). It is "about undertaking action and studying that action as it takes place" (Coghlan and Shani 2005:533). In this way, Lewin combined the positivistic approach to social science, i.e., objective and systematic measurement and quantification of social phenomena by way of data collection, with interventions to provide practical solutions to social issues (Bargal 2008).

Several principles guide action research (Susman and Evered 1978, Bargal et al. 1992, Bargal 2006, 2008), but the fundamental premise is that of a cyclical problem-solving and learning process in which research, i.e., planning and fact finding, leads to action, i.e., intervention, followed by the evaluation of action to inform research, further action, and so forth. The coupling of theory and practice ultimately means that both theoretical and practical issues can be simultaneously solved, not to mention the fact that methodological rigour can be upheld (McKay and Marshall 2001). Even though the fundamental principles of action research are now well described, it is unfortunate that many applications of action research have disregarded the essential components of the scientific method. As a result, critics of this style of action research have raised concerns regarding researcher nonindependence and impartiality, the reliance on anecdotal, subjective assessment of outcomes to reflect program impact, and the inherent difficulty in generalizing results (Greenwood and Levin 1999). Oftentimes, the reporting of action research fails to articulate the research process or design, and instead focuses on describing the field context and content of the study (McKay and Marshall 2001). These criticisms suggest a serious imbalance between theory and practice, in that the roles and/or goals of the theorist or researcher, to design robust experiments and to measure quantifiable outcomes, have become background, and the priorities of the applied psychologist or practitioner, to involve the community to make a change, have come to the fore. This disparity is not surprising given the enormous challenge inherent in the conduct of action research, i.e., the coordination among different types of scientists, practitioners, community partners, and other stakeholders (Stokols 2006). Compounding this challenge, many researchers, at least in the field of social psychology, have not yet fully grasped the concept of ecology and therefore tend to confine their research programs to the laboratory setting (Oishi and Graham 2010), or to conduct applied research using a hit and run style of consultation (Stokols 2006), or to simply uncritically assemble the views of stakeholders.

Lewin was an experimentalist and adhered to the scientific method, as demonstrated by his extensive use of controlled or 
comparative experimental designs to evaluate the impact of various interventions (Lewin 1947b, Bargal et al. 1992). He supported the use of quasi-experimental research designs (Lewin $1947 c$ ), often in conjunction with qualitative and observational assessments (Lewin 1946), but he emphasized the importance of complementing diagnosis, of the problem via interview or survey, with "comparative studies of the effectiveness of various techniques of change" (Lewin 1946:37) and "properly selected groups and adequately defined controls" (Lewin 1947a:152), and stressed the importance of systematic, objective measurement, including the careful construction of both operational and conceptual definitions, and evaluation (Lewin 1947b).

Adherence to the scientific method can be challenging when conducting action research, especially at macrolevels of analysis in which the number of available units can be inadequate, in which there is limited control over interventions and their delivery, and in which participatory decision making is a vital feature of the intervention. However, a Lewinian approach to action research does not require that all aspects of cyclical duality in a research program must be purely experimental. For example, nonexperimental field research can be complemented and informed by basic experiments conducted in the laboratory. Additionally, through systematic, critical, and creative approaches to alternative research design and measurement, it is possible to design field studies that allow interventions to be implemented and evaluated rigorously (Zanna 2011). Without commitment to searching for these novel solutions, it will always be impossible to assess the potency, durability, and generalizability of any intervention designed to produce change.

\section{CONCLUSION: IMPLICATIONS OF A LEWINIAN APPROACH FOR SOCIAL-ECOLOGICAL RESILIENCE}

No one doubts the importance of understanding resilience in social-ecological systems. The development of resilience ideas in social ecology, for example through the Resilience Alliance and through the growth of sustainability science, has been marked. Our ability to analyze and understand coupled social-ecological systems, to better grasp the interconnections and interdependencies between the material and the symbolic universes, from immediate, local contexts through to macro, global systems, is essential for us to avoid, mitigate, or adapt to major ecosystem changes to our planet.

Many strands of work in different parts of the social sciences over the last century intersect with current resilience thinking, though often not in forms that are directly recognizable. Our aim has been to articulate Kurt Lewin's field theoretical approach to analyzing social systems and social change, and to suggest this approach has much to offer any effort at comprehending coupled socialecological systems, and especially to any effort to intervene directly to produce deliberate transformational change in such systems. The fundamental principles of Lewin's field theory, which are primarily relevant to social-ecological resilience are summarized as:

1. Systems are structural and dynamic. The dynamism arises from tensions between conflicting elements within and between systems. Constant tension means that systems are constantly changing. Identifying key points of tension opens opportunities to produce durable, systemic change.
2. When systems involve humans, subjective environments are as important as objective environments. Within subjective systems, motivational elements are as important as perceptual ones. Behavior is driven teleologically as much as historically, and those motive sets often conflict. The future and the past unite in the life space, as do intraindividual, interindividual, group, and ideological processes.

3. How people perceive and interact with their environment is an essential part of knowing when and how to intervene to stimulate system change. But these perceptual and motivational elements are often difficult to directly observe or measure, i.e., individuals are often unaware of, and/or unable to articulate, the many forces acting to influence their behavior. Hence, a variety of research methods is required.

4. Social systems operate in, and tend to be motivated to operate in, a state of quasi-stationary equilibrium. Many upsets to the system are temporary, followed by a return to that state of quasi-stationary equilibrium. Producing an intervention, which has durable change, requires shifting the system to a new state of quasi-stationary equilibrium.

5. Interventions aimed at producing behavioral change in one part of a system can have no effect, or unintended effects, because the behavior is connected to multiple parts of the system, which are ignored by the intervention. Behaviors and systems rarely change because of changes in a single motivating force. A complementary suite of interventions, which counter lever different forces at different levels in the system, can help circumvent unintended effects and is more likely to create long-lasting system change.

Lewin's field theory is expressed in such abstract terms that it is almost impossible to imagine a situation in which it does not, or cannot, apply. Despite that, there are certainly areas in which the theory is underdeveloped. Here are three of them.

First, we alluded earlier to the importance of the variety of different capitals available to actors as resources to draw upon to achieve desired goals or to avoid undesired ones. The capitals approach is familiar to most resilience researchers (e.g., the five capitals framework; Bebbington 1999). Field theory has not paid adequate attention to how different capitals are identified by social actors, or hidden to them, or to how the capitals interact with one another in a system, let alone how such capitals are operationalized. The possibility of conflict among different capitals introduces a second undertheorized area.

The notion of conflict, whether between capitals or people or groups, raises questions of power, and especially of power differences. Lewin's field theory is almost silent on questions of differential access to status and resources, on issues of who controls society's major assets, and on the effects of disempowerment. These are not issues beyond field theory, in principle, but the hard work to theorize how these play out within a Lewinian framework has yet to be done. A footnote to questions of power must also note that researchers themselves occupy particular positions within the social matrix, usually positions of some sorts of power but also lacking in other sorts. A full analysis of power must therefore also be adequate self-reflexively. 
Related to the idea of conflict and power, we note an apparent paradox in articulating social science efforts with those from resilience approaches: most efforts in the social sciences, including Lewin's, are oriented with a deliberate view of disrupting (social) systems to produce system change; however most resilience approaches appear oriented to understanding how (ecological) systems can be preserved against the insults and injuries that humans inflict upon them. We do not assert or accept that the paradox is necessary or fundamental, but we suggest value in developing more fully a dialectical approach, which seeks to reconcile competing pressures and desires for change and for stasis.

Finally, we suggest that field theory has not dealt adequately with the intricacies of combining different levels of analysis within a single framework. Temptations of reification and reduction persist, but both must be resisted. How we can conceptualize constructs and processes at different levels without committing such logical sins remains to be fully articulated.

Despite the danger of being too encompassing, and despite being underdeveloped on a number of fronts, we suggest that a Lewinian field theoretical approach affords a valuable framework to researchers and practitioners working at the interface between human, social, and natural systems.

Responses to this article can be read online at: http://www.ecologyandsociety.org/issues/responses. $\mathrm{php} / 7260$

\section{Acknowledgments:}

We thank Samantha Stone-Jovicich, Zoe Leviston, Lilly LimCamacho, Justine Lacey, and two anonymous reviewers for their comments on earlier drafts of this paper, and CSIRO's Climate Adaptation Flagship for support.

\section{LITERATURE CITED}

Adger, W. N., T. P. Hughes, C. Folke, S. R. Carpenter, and J. Rockström. 2005. Social-ecological resilience to coastal disasters. Science 309:1036-1039. http://dx.doi.org/10.1126/science.1112122

Bahadur, A. V., M. Ibrahim, and T. Tanner. 2013. Characterising resilience: unpacking the concept for tackling climate change and development. Climate and Development 5:55-65. http://dx.doi. org/10.1080/17565529.2012.762334

Bargal, D. 2006. Personal and intellectual influences leading to Lewin's paradigm of action research: towards the 60th anniversary of Lewin's 'action research and minority problems' (1946). Action Research 4:367-388. http://dx.doi. org/10.1177/1476750306070101

Bargal, D. 2008. Action research: a paradigm for achieving social change. Small Group Research 39:17-27. http://dx.doi. org/10.1177/1046496407313407

Bargal, D., M. Gold, and M. Lewin. 1992. Introduction: the heritage of Kurt Lewin. Journal of Social Issues 48:3-13. http:// dx.doi.org/10.1111/j.1540-4560.1992.tb00879.x
Barker, R. G. 1968. Ecological psychology: concepts and methods for studying the environment of human behavior. Stanford University Press, Stanford, California, USA.

Baron, R., and S. Misovich. 1993. An integration of Gibsonian and Vygotskian perspectives on changing attitudes in group contexts. British Journal of Social Psychology 32:53-70. http://dx. doi.org/10.1111/i.2044-8309.1993.tb00985.X

Bebbington, A. 1999. Capitals and capabilities: a framework for analysing peasant viability, rural livelihoods and poverty. World Development 27:2021-2044. http://dx.doi.org/10.1016/S0305-750X (99)00104-7

Biggs, R., M. Schlüter, D. Biggs, E. L. Bohensky, S. BurnSilver, G. Cundill, V. Dakos, T. M. Daw, L. S. Evans, K. Kotschy, A. M. Leitch, C. Meek, A. Quinlan, C. Raudsepp-Hearne, M. D. Robards, M. L. Schoon, L. Schultz, and P. C. West. 2012. Toward principles for enhancing the resilience of ecosystem services. Annual Review of Environmental Resources 37:421-448. http://dx. doi.org/10.1146/annurev-environ-051211-123836

Bohensky, E., S. Stone-Jovicich, S. Larson, and N. Marshall. 2010. Adaptive capacity in theory and reality: implications for governance in the Great Barrier Reef region. Pages 23-41 in D. Armitage and R. Plummer, editors. Adaptive capacity and environmental governance. Springer-Verlag, Berlin, Germany. http://dx.doi.org/10.1007/978-3-642-12194-4_2

Bronfenbrenner, U. 1979. The ecology of human development. Harvard University Press, Cambridge, Massachusetts, USA.

Brown, K. 2014. Global environmental change I: a social turn for resilience? Progress in Human Geography 38:107-117. http://dx. doi.org/10.1177/0309132513498837

Burnes, R. 2004. Kurt Lewin and the planned approach to change: a re-appraisal. Journal of Management Studies 41:977-1002. http://dx.doi.org/10.1111/j.1467-6486.2004.00463.x

Carpenter, S., B. Walker, J. M. Anderies, and N. Abel. 2001. From metaphor to measurement: resilience of what to what? Ecosystems 4:765-781. http://dx.doi.org/10.1007/s10021-001-0045-9

Cartwright, D. 1951. Field theory in social science: selected theoretical papers. Greenwood, Westport, Connecticut, USA.

Cialdini, R. B., C. A. Kallgren, and R. R. Reno. 1991. A focus theory of normative conduct: a theoretical refinement and reevaluation of the role of norms in human behavior. Advances in Experimental Social Psychology 24:201-234. http://dx.doi. org/10.1016/S0065-2601(08)60330-5

Cialdini, R. B., R. R. Reno, and C. A. Kallgren. 1990. A focus theory of normative conduct: recycling in concept of norms to reduce littering in public places. Journal of Personality and Social Psychology 58:1015-1026. http://dx.doi.org/10.1037/0022-3514.58.6.1015

Cialdini, R. B., and M. R. Trost. 1998. Social influence: social norms, conformity and compliance. Pages 151-192 in D. T. Gilbert, S. T. Fiske, and G. Lindsey, editors. Handbook of social psychology. Fourth edition. McGraw-Hill, New York, New York, USA.

Coghlan, D., and A. B. R. Shani. 2005. Roles, politics, and ethics in action research design. Systematic Practice and Action Research 18:533-546. http://dx.doi.org/10.1007/s11213-005-9465-3 
Cutter, S. L., L. Barnes, M. Berry, C. Burton, E. Evans, E. Tate, and J. Webb. 2008. A place-based model for understanding community resilience to natural disasters. Global Environmental Change 18:598-606. http://dx.doi.org/10.1016/j.gloenvcha.2008.07.013

Dellavigna, S. 2009. Psychology and economics: evidence from the field. Journal of Economic Literature 47:315-372. http://dx. doi.org/10.1257/jel.47.2.315

Deutsch, M. 1968. Field theory in social psychology. Pages 412-487 in G. Lindzey and E. Aronson, editors. Handbook of social psychology. Second Edition. Addison-Wesley, Reading, Massachusetts, USA.

Dolan, P., M. Hallsworth, D. Halpern, D. King, R. Metcalfe, and I. Vlaev. 2012. Influencing behaviour: the mindspace way. Journal of Economic Psychology 33:264-277. http://dx.doi.org/10.1016/j. joep.2011.10.009

Dolan, P., M. Hallsworth, D. Halpern, D. King, and I. Vlaev. 2010. Mindspace. Influencing behaviour through public policy. Institute for Government and Cabinet Office, London, UK. [online] URL: http://www.instituteforgovernment.org.uk/publications/ mindspace

Fearne, A., M. G. Martinez, and B. Dent. 2012. Dimensions of sustainable value chains: implications for value chain analysis. Supply Chain Management 17:575-581. http://dx.doi. org/10.1108/13598541211269193

Folke, C. 2006. Resilience: the emergence of a perspective for social-ecological systems analyses. Global Environmental Change 16:253-267. http://dx.doi.org/10.1016/j.gloenvcha.2006.04.002

Folke, C., S. R. Carpenter, B. Walker, M. Scheffer, T. Chapin, and J. Rockström. 2010. Resilience thinking: integrating resilience, adaptability and transformability. Ecology and Society 15(4): 20. [online] URL: http://www.ecologyandsociety.org/vol15/iss4/ $\underline{\operatorname{art} 20 /}$

Gibson, J. J. 1966. The senses considered as perceptual systems. Houghton Mifflin, Boston, Massachusetts, USA.

Gibson, J. J. 1979. The ecological approach to visual perception. Houghton Mifflin, Boston, Massachusetts, USA.

Goldstein, N. J., R. B. Cialdini, and V. Griskevicius. 2008. A room with a viewpoint: using social norms to motivate environmental conservation in hotels. Journal of Consumer Research 35:472-482. http://dx.doi.org/10.1086/586910

Greenwald, A. G., and M. R. Banaji. 1995. Implicit social cognition: attitudes, self-esteem, and stereotypes. Psychological Review 102:4-27. http://dx.doi.org/10.1037/0033-295X.102.1.4

Greenwood, D., and M. Levin. 1999. Introduction to action research: social research for social change. Sage, Thousand Oaks, California, USA.

Gunderson, L. H., S. R. Carpenter, C. Folke, P. Olsson, and G. D. Peterson. 2006. Water RATs (resilience, adaptability, and transformability) in lake and wetland social-ecological systems. Ecology and Society 11(1): 16. [online] URL: http://www. ecologyandsociety.org/vol11/iss1/art16/

Hargreaves, T., M. Nye, and J. Burgess. 2008. Social experiments in sustainable consumption: an evidence-based approach with potential for engaging low-income communities. Local Environment 13:743-758. http://dx.doi.org/10.1080/13549830802475666

Heft, H. 2001. Ecological psychology in context: James Gibson, Roger Barker, and the legacy of William James's radical empiricism. Erlbaum, Mahwah, New Jersey, USA.

Heft, H. 2003. Affordances, dynamic experience, and the challenge of reification. Ecological Psychology 15:149-180. http:// dx.doi.org/10.1207/S15326969ECO1502 4

Heft, H. 2013. An ecological approach to psychology. Review of General Psychology 17:162-167. http://dx.doi.org/10.1037/ $\underline{\mathrm{a} 0032928}$

Hobson, K. 2003. Thinking habits into action: the role of knowledge and process in questioning household consumption practices. Local Environment 8:95-112.

Hormuth, S. E. 1999. Social meaning and social context of environmentally-relevant behavior: shopping, wrapping, and disposing. Journal of Environmental Psychology 19:277-286. http://dx.doi.org/10.1006/jevp.1999.0134

James, P., K. Tzoulas, M. D. Adams, A. Barber, J. Box, J. Breuste, T. Elmqvist, M. Frith, C. Gordon, K. L. Greening, J. Handley, S. Haworth, A. E. Kazmierczak, M. Johnston, K. Korpela, M. Moretti, J. Niemelä, S. Pauleit, M. H. Roe, J. P. Sadler, and C. Ward Thompson. 2009. Towards an integrated understanding of green space in the European built environment. Urban Forestry and Urban Greening 8:65-75. http://dx.doi.org/10.1016/j. ufug.2009.02.001

Jenkins, H. S. 2008. Gibson's "affordances": evolution of a pivotal concept. Journal of Scientific Psychology December:34-45. [online] URL: http://www.psyencelab.com/images/ Gibsons Affordances Evolution of a Pivotal Concept.pdf

Kahneman, D. 2003. Maps of bounded rationality: psychology for behavioral economics. American Economic Review 93:1449-1475. http://dx.doi.org/10.1257/000282803322655392

Kahneman, D. 2011. Thinking, fast and slow. Penguin, New York, New York, USA.

Kaplan, S., and M. G. Berman. 2010. Directed attention as a common resource for executive functioning and self-regulation. Perspectives on Psychological Science 5:43-57. http://dx.doi. org/10.1177/1745691609356784

Klein, R. J. T., R. J. Nicholls, and F. Thomalla. 2003. Resilience to natural hazards: how useful is this concept? Environmental Hazards 5:35-45. http://dx.doi.org/10.1016/j.hazards.2004.02.001

Kurz, T. 2002. The psychology of environmentally sustainable behavior: fitting together pieces of the puzzle. Analyses of Social Issues and Public Policy 2:257-278. http://dx.doi.org/10.1111/ j.1530-2415.2002.00041.X

Kurz, T., N. Donaghue, and I. Walker. 2005. Utilizing a socialecological framework to promote water and energy conservation: a field experiment. Journal of Applied Social Psychology 35:1281-1300. http://dx.doi.org/10.1111/j.1559-1816.2005.tb02171. $\underline{x}$

Lewin, K. 1946. Action research and minority problems. Journal of Social Issues 2:34-46. http://dx.doi.org/10.1111/j.1540-4560.1946. $\underline{\text { tb02295.x }}$ 
Lewin, K. 1947c. Frontiers in group dynamics: concept, method and reality in social science; social equilibria and social change. Human Relations 1:5-41. http://dx.doi.org/10.1177/001872674700100103

Lewin, K. 1947a. Frontiers in group dynamics II: channels of group life; social planning and action research. Human Relations 1:143-153. http://dx.doi.org/10.1177/001872674700100201

Lewin, K. 1947b. Group decision and social change. Pages 330-344 in T. M. Newcomb and E. L. Hartley, editors. Readings in social psychology. Henry Holt, New York, New York, USA.

Lewin, K. 1951, c1940. Formalization and progress in psychology. Pages 1-29 in D. Cartwright, editor. Field theory in social science. Greenwood, Westport, Connecticut, USA.

Lewin, K. 1951, c1942. Field theory and learning. Pages 60-86 in D. Cartwright, editor. Field theory in social science. Greenwood, Westport, Connecticut, USA.

Lewin, K. 1951, c1943-1944. Problems of research in social psychology. Pages 155-169 in D. Cartwright, editor. Field theory in social science. Greenwood, Westport, Connecticut, USA.

Lewin, K. 1951, c1943a. Defining the "field at a given time". Pages 43-59 in D. Cartwright, editor. Field theory in social science. Greenwood, Westport, Connecticut, USA.

Lewin, K. 1951, c1943b. Psychological ecology. Pages 170-187 in D. Cartwright, editor. Field theory in social science. Greenwood, Westport, Connecticut, USA.

Lewin, K. 1951, c1946. Behavior and development as a function of the total situation. Pages in D. Cartwright, editor. Field theory in social science. Greenwood, Westport, Connecticut, USA.

Marshall, N. A., and P. A. Marshall. 2007. Conceptualizing and operationalizing social resilience within commercial fisheries in Northern Australia. Ecology and Society 12(1): 1. [online] URL: http://www.ecologyandsociety.org/vol12/iss1/art1/

McCarthur, L. Z., and R. M. Baron. 1983. Toward an ecological theory of social perception. Psychological Review 90:215-238. http://dx.doi.org/10.1037/0033-295X.90.3.215

McKay, J., and P. Marshall. 2001. The dual imperatives of action research. Information Technology and People 14:46-59. http://dx. doi.org/10.1108/09593840110384771

Metcalfe, R., and P. Dolan. 2012. Behavioural economics and its implications for transport. Journal of Transport Geography 24:503-511. http://dx.doi.org/10.1016/j.jtrangeo.2012.01.019

Nisbett, R. E., and T. D. Wilson. 1977. Telling more than we can know: verbal reports on mental processes. Psychological Review 84:231-259. http://dx.doi.org/10.1037/0033-295X.84.3.231

Nolan, J. M., P. W. Schultz, R. B. Cialdini, N. J. Goldstein, and V. Griskevicius. 2008. Normative social influence is underdetected. Personality and Social Psychology Bulletin 34:913-923. http://dx.doi.org/10.1177/0146167208316691

Oishi, S. 2014. Socioecological psychology. Annual Review of Psychology 65:581-609. http://dx.doi.org/10.1146/annurevpsych-030413-152156

Oishi, S., and J. Graham. 2010. Social ecology: lost and found in psychological science. Perspectives on Psychological Science 5:356-377. http://dx.doi.org/10.1177/1745691610374588
Ponomarov, S. Y., and M. C. Holcomb. 2009. Understanding the concept of supply chain resilience. International Journal of Logistics 20:124-143. http://dx.doi.org/10.1108/09574090910954873

Schoggen, P. 1989. Behavior settings: a revision and extension of Roger G. Barker's "ecological psychology." Stanford University Press, Stanford, California, USA.

Shove, E. 2003a. Converging conventions of comfort, cleanliness and convenience. Lancaster University Press, Lancaster, UK.

Shove, E. 2003b. Users, technologies and expectations of comfort, cleanliness and convenience. Innovation 16:193-206. http://dx.doi. org/10.1080/13511610304521

Soosay, C., A. Fearne, and B. Dent. 2012. Sustainable value chain analysis - a case study of Oxford Landing from "vine to dine". Supply Chain Management 17:68-77. http://dx.doi. org/10.1108/13598541211212212

Staats, H., P. Harland, and H. A. M. Wilke. 2004. Effecting durable change: a team approach to improve environmental behavior in the household. Environment and Behavior 36:341-367. http://dx.doi.org/10.1177/0013916503260163

Stokols, D. 2006. Toward a science of transdisciplinary action research. American Journal of Community Psychology 38:63-77. http://dx.doi.org/10.1007/s10464-006-9060-5

Stokols, D., R. Perez Lejano, and J. Hipp. 2013. Enhancing the resilience of human-environment systems: a social ecological perspective. Ecology and Society 18(1): 7. http://dx.doi. org/10.5751/ES-05301-180107

Susman, G. I., and R. D. Evered. 1978. An assessment of the scientific merits of action research. Administrative Science Quarterly 23:582-603. http://dx.doi.org/10.2307/2392581

Thaler, R. H., and C. R. Sunstein. 2008. Nudge: improving decisions about health, wealth, and happiness. Yale University Press, New Haven, Connecticut, USA.

Tidball, K. G., and M. E. Krasny. 2007. From risk to resilience: what role for community greening and civic ecology in cities? Pages 149-164 in A. E. J. Wals, editor. Social learning towards a more sustainable world. Wageningen Academic, Wageningen, The Netherlands.

Verplanken, B., and W. Wood. 2006. Interventions to break and create consumer habits. Journal of Public Policy and Marketing 25:90-103. http://dx.doi.org/10.1509/jppm.25.1.90

Walker, B. H., J. M. Anderies, A. P. Kinzig, and P. Ryan. 2006. Exploring resilience in social-ecological systems: comparative studies and theory development. Ecology and Society Special Feature 22. [online] URL: http://www.ecologyandsociety.org/ issues/view.php? $\mathrm{sf}=22$

Walker, B. H., C. S. Holling, S. R. Carpenter, and A. Kinzig. 2004. Resilience, adaptability and transformability in social-ecological systems. Ecology and Society 9(2): 5. [online] URL: http://www. ecologyandsociety.org/vo19/iss2/art5/

Webb, E. J., D. T. Campbell, R. D. Schwartz, and L. Sechrest. 1966. Unobtrusive measures: nonreactive research in the social sciences. Rand McNally, Chicago, Illinois, USA. 
Zanna, M. P. 2011. While waiting for Nature to take her course: there's nothing so practical as a good...design. Journal of Social Issues 67:651-662. http://dx.doi.org/10.1111/j.1540-4560.2011.01720. $\underline{x}$

Zhou, H., J. Wang, J. Wan, and H. Jia. 2010. Resilience to natural hazards: a geographic perspective. Natural Hazards 53:21-41. http://dx.doi.org/10.1007/s11069-009-9407-y 